\title{
Diagnosing dementia: Do we get it right?
}

\author{
Ann C Homer, M Honavar, P L Lantos, I R Hastie, J M Kellett, P H Millard
}

\begin{abstract}
To find out whether the diagnosis of dementia agreed with findings at necropsy a detailed assessment of 27 elderly patients (mean age 82 (range 7094)) presenting with dementia was conducted at a combined department of geriatric medicine and psychiatry for the elderly. On the basis of the results the cause of the dementia was diagnosed clinically. Neuropathological examinations were performed after death. The clinical diagnosis made during life was not supported by the findings at necropsy in 11 cases. Alzheimer's disease was overdiagnosed in life (13 cases, of which only six were confirmed at necropsy). Although the clinical investigation was limited by availability of resources, neither cranial computed tomography nor the Hachinski score helped to distinguish between multi-infarct dementia and Alzheimer's disease in this age group.
\end{abstract}

This study confirms the value of neuropathological studies in the precise diagnosis of dementia.

\section{Introduction}

Since 1981 one patient with suspected dementia has been admitted each week to a specially designated bed in the combined department of geriatric medicine and psychiatry for the elderly at St George's Hospital. Over 400 patients have been evaluated. Any elderly patient with suspected dementia who is referred to the department and lives in the catchment area is eligible for admission. Half the patients are referred by consultants in geriatric medicine and half by consultant psychiatrists for the elderly. The rate of admission is limited to one patient a week because only one computed tomographic scan is available each week at Atkinson Morley's Hospital.

The box gives details of the assessment carried out during the week. Great importance is attached to the history of behavioural changes. Accordingly, as many sources as possible are used to compile this because accurate information is hard to obtain from a confused elderly patient who has become socially isolated. Physical examination is carried out by the senior house officer in geriatric medicine under the supervision of the consultant geriatrician in charge of the ward (IRH). The entire examination follows a set form, and each new senior house officer watches a video showing how the examination is to be conducted before starting.

In this study we compared our clinical diagnoses based on this assessment with the results of neuropathological studies in the first 27 patients investigated.

\section{Patients and methods}

We presented the results of our investigations and the history each week at a multidisciplinary meeting and arrived at a consensus decision on the most likely cause for the patient's dementia. The Hachinski score was calculated (table I): the higher the score the more likely that the dementia is due to cerebrovascular disease. ${ }^{1}$ Relative preservation of the personality was defined as the presence of insight. The results were explained to both patient 'and carers six weeks later during an outpatient appointment at which time permission for necropsy was requested.

After the patient's death permission was confirmed and a general necropsy carried out by the duty
Investigations performed during week of admission

History: from as many sources as possible-for example, home help, carer, general practitioner

Physical examination

Nursing assessment (five point rating scale): dressing, mobility, continence, feeding, self care, sleep, mood, social activity, communication, interests, orientation, cooperation, restlessness

Occupational therapist's assessment: ability to wash, dress, toilet, make tea, open locks, telephone

Abbreviated mental test score

Nelson word reading test

Cortical function tests: object recognition, phasia, agnosia, praxis, right-left orientation, calculia, reasoning, motor sequencing

Assessment of handwriting

Assessment of insight

Biochemical and haematological screening, including for vitamin $B_{12}$ and folate concentrations, Wassermann reaction, thyroid function

Lumbar puncture; microscopic analysis of cerebrospinal fluid and estimation of protein concentration

Microscopic analysis and culture of urine

Electrocardiography

Echocardiography

Chest radiography

Cranial computed tomography

pathologist. The brain was removed intact and sent to the department of neuropathology at the Institute of Psychiatry for detailed neuropathological study. The brains were weighed and sliced in the coronal plane. Blocks of tissue were taken from the frontal, parietal, temporal, and occipital lobes; the deep grey matter including the amygdala and lentiform and caudate nuclei; the nucleus basalis of Meynert; the thalamus; the cerebellum; and the brain stem. Any macroscopic focal lesions were also sampled. Sections were stained with haematoxylin and eosin, with luxol fast blue and cresyl violet, with congo red, by the silver impregnation method of Glees et $a l,{ }^{2}$ and, when appropriate, immunocytochemically to show glial fibrillary acidic protein. Blocks were prepared and examined by electron microscopy.

The diagnosis of Alzheimer's disease was based on the presence of large numbers of neurofibrillary tangles, neuritic plaques, granulovacuoles, and Hirano bodies in the medial temporal structures including the hippocampus; neurofibrillary tangles and neuritic plaques in the neocortex; and neurofibrillary tangles in the brain stem. The presence of appreciable deposits of amyloid in the leptomeningeal and cortical vessels, with or without Alzheimer's disease, was considered to indicate amyloid (congophilic) angiopathy. The dementia was thought to be due to cerebrovascular disease when multiple infarcts of various sizes were seen in the cerebral cortex, white matter, and basal ganglia. Mixed Alzheimer's disease and cerebrovascular disease was diagnosed when pathological features of either condition were thought to be sufficient to have caused dementia. ${ }^{3}$

Statistical analysis was performed with the $\chi^{2}$ test with Yates's correction for small numbers unless otherwise stated.

\section{Results}

By 1 January 1987, 27 patients (10 men and 17 women; mean age 82 (range 70-94)) had died and had a postmortem examination. Fourteen had been referred by consultants in geriatric medicine and 13 by consult- 
TABLE II-Clinical diagnoses in patients presenting with dementia compared with neuropathological diagnoses made after death

\begin{tabular}{lcccc}
\hline & \multicolumn{3}{c}{ Neuropathological diagnosis } \\
\cline { 2 - 4 } Clinical diagnosis & $\begin{array}{c}\text { Alzheimer's Multi-infarct } \\
\text { disease } \\
(\mathrm{n}=6)\end{array}$ & $\begin{array}{c}\text { Mixed } \\
\text { dementia } \\
(\mathrm{n}=16)\end{array}$ & $\begin{array}{c}\text { picture } \\
(\mathrm{n}=1)\end{array}$ & $\begin{array}{c}\text { Othert } \\
(\mathrm{n}=4)\end{array}$ \\
\hline $\begin{array}{c}\text { Alzheimer's disease } \\
(\mathrm{n}=13)\end{array}$ & 6 & 4 & & 3 \\
$\begin{array}{c}\text { Multi-infarct } \\
\text { dementia }(\mathrm{n}=10)\end{array}$ & & 9 & & 1 \\
$\begin{array}{c}\text { Mixed picture }(\mathrm{n}=2) \\
\text { Other } \neq(\mathrm{n}=2)\end{array}$ & 1 & 1 & \\
\end{tabular}

^Two cases of Alzheimer's disease with amyloid angiopathy and four of Alzheimer's disease alone.

†Progressive multifocal leucoencephalopathy, diffuse Lewy body disease, amyloid angiopathy, and normal brain.

$\ddagger$ Benign senescent forgetfulness and normal pressure hydrocephalus.

ants in psychiatry. Most patients had had cognitive impairment for a minimum of two or three years before admission (range six months to five years). Table II compares the clinical diagnoses with the neuropathological diagnoses made at necropsy; the average time between the onset of illness and death was 3.3 years (range 1.5-6.0 years). Alzheimer's disease was overdiagnosed and cerebrovascular disease underdiagnosed during life. The clinical diagnosis agreed with the neuropathological diagnosis in 16 cases. Table III lists conditions found at general necropsy that had not been suspected. Table IV relates clinical features to the diagnoses at necropsy. A positive Wassermann reaction was found in one patient, but at necropsy mild cerebrovascular disease was found. A patient with progressive multifocal leucoencephalopathy had an underlying gastric carcinoma, which was not diagnosed until necropsy. Table $\mathrm{V}$ gives the scores on the Hachinski ischaemic scale categorised by neuropathological diagnosis. Eighteen patients scored $\leqslant 4$, only four scored $\geqslant 7$.

Cranial computed tomography was performed on 23 patients; two patients refused the procedure, and two were too restless for it. Most of the computed tomograms (17) showed only atrophic changes; two showed one or more infarcts; one showed atrophy and

TABLE IV-Clinical features related to findings at necropsy

\begin{tabular}{|c|c|c|c|}
\hline & $\begin{array}{l}\text { Cerebro- } \\
\text { vascular } \\
\text { disease } \\
(n=16)\end{array}$ & $\begin{array}{l}\text { Alzheimer's } \\
\text { disease } \\
(\mathrm{n}=4)\end{array}$ & $\begin{array}{l}\text { Other } \\
(\mathrm{n}=7)\end{array}$ \\
\hline Family history of dementia & $1^{\star}$ & 3 & \\
\hline Current cigarette smokers ( $>10 /$ day $)$ & $9 \dagger$ & 1 & \\
\hline $\begin{array}{l}\text { History of hypertension, ischaemic } \\
\text { heart disease, or stroke }\end{array}$ & $12 \dagger$ & & 3 \\
\hline Atrial fibrillation on & & & 1 \\
\hline Ischaemia on electrocardiography & $6 \neq$ & 1 & $\begin{array}{l}1 \\
3\end{array}$ \\
\hline Focal neurological signs & 4 & 1 & 2 \\
\hline \multicolumn{4}{|l|}{ Insight: } \\
\hline None & 5 & 3 & 3 \\
\hline Partial & 5 & 1 & \\
\hline Full & 3 & & \\
\hline
\end{tabular}

${ }^{\star} \mathrm{p}<0 \cdot 01$, cerebrovascular disease $v$ Alzheimer's disease

$\mathrm{p}<0.05$, cerebrovascular disease $v$ Alzheimer's disease plus other.

$\neq \mathrm{p}<0 \cdot 05$, cerebrovascular disease $v$ Alzheimer's disease (one tailed) $\chi^{2}$ test.

TABLE V - Number of patients with each Hachinski score by diagnosis at necropsy

\begin{tabular}{|c|c|c|c|c|c|c|c|c|c|c|c|}
\hline & \multicolumn{11}{|c|}{ Hachinski score } \\
\hline & 0 & 1 & 2 & 3 & 4 & 5 & 6 & 7 & 8 & & 11 \\
\hline Cerebrovascular disease & 2 & 2 & 1 & 2 & 2 & 2 & 1 & 2 & 1 & & 1 \\
\hline Alzheimer's disease & 2 & & 1 & & 1 & & & & & & \\
\hline Mixed picture & & 1 & & & & & & & & & \\
\hline Amyloid angiopathy & & 1 & & & & & & & & & \\
\hline Diffuse Lewy body disease & & 1 & & & & & & & & & \\
\hline $\begin{array}{l}\text { Alzheimer's disease with } \\
\text { amyloid angiopathy }\end{array}$ & & & 1 & 1 & & & & & & & \\
\hline $\begin{array}{l}\text { Progressive multifocal } \\
\text { leucoencephalopathy }\end{array}$ & & & & & & 1 & & & & & \\
\hline No abnormality & & & & & & & 1 & & & & \\
\hline
\end{tabular}

cerebrovascular changes; two were normal; and one showed obstructive hydrocephalus. The average time between computed tomography and death was 17 months (range 1-35 months).

\section{Discussion}

Most of the patients whom we studied had multiple diseases as would be expected in this age group, but several previously unsuspected conditions were found at necropsy (table IV). One of the patients who was found to have carcinoma of the stomach was also suffering from progressive multifocal leucoencephalopathy: electron microscopy showed papovavirus particles in the brain. This patient died within two months after being investigated, but one of the difficulties of a prospective study of this type is the changes that may occur during the time between investigation and death (average 1.3 years). Another important, unsuspected finding at necropsy was that one patient had a normal brain for her age. In retrospect she probably had pseudodementia caused by depression, a diagnosis that we considered but thought unlikely when she was alive. Interestingly, because her Hachinski score was quite high (7) we thought that she had multiple infarcts (table VI).

The proportion of patients found to have multiinfarct dementia was much higher than has generally been reported. ${ }^{45}$ Tomlinson et al reported brain changes of the Alzheimer type in half of the demented patients in their study, multiple infarcts in $17 \%$, and mixed changes typical of Alzheimer's disease and vascular changes in $18 \% .^{3}$ Higher proportions of patients with multi-infarct dementia, however, have been reported, and the proportion varies considerably with geographical location and selection bias. ${ }^{6}$ Selection bias is an important factor. We studied the results arising from a clinical service designed to investigate suspected dementia. Any elderly patient with suspected dementia was eligible to be admitted for investigation, but clinicians were more likely to refer patients whose dementia was not immediately obvious or who had unusual features posing a diagnostic problem. Selection bias may also operate with respect to those patients who undergo necropsy.

We underdiagnosed multi-infarct dementia during life. This may have been partly because we placed too much importance on the features listed in the Hachinski score and on the overall score itself. Only a quarter of the patients with multi-infarct dementia had focal neurological signs. Evidence of vascular disease or a history of current cigarette smoking, hypertension, or coronary disease most often pointed to cerebrovascular disease.

Hachinski et al devised the Hachinski score in 1975 when they showed a bimodal distribution of scores in 24 patients. $^{1}$ They found a clear cut off point: 10 patients scored $\geqslant 7$ or more and were said to have multi-infarct dementia, and 14 patients scored $\leqslant 4$ and were said to have primary degenerative dementia. The patients they studied were on average 20 years younger than ours. The diagnoses were made with cerebral blood flow techniques, but neuropathological examination was not performed after death to confirm them. We did not observe a bimodal distribution. Only four patients scored $\geqslant 7$, although all of these had multi-infarct dementia. Most of the patients in our age group scored too low for the value to be of much use in differentiating between them.

Few studies have prospectively assessed the Hachinski score in this age group and verified the results with pathological examination. ${ }^{7}$ Gustafson et al studied dementia in 57 patients and verified the diagnosis in 28 , but the onset of illness occurred between the ages of 40 and $65 .{ }^{8} \mathrm{~A}$ more comparable 
group of elderly patients was studied by Rosen et al, who examined retrospectively the case notes of 14 patients who had died of dementia and whose brains were available for neuropathological examination." Four of their patients with Alzheimer's disease scored five or less and nine with multi-infarct disease or a mixed picture scored 7-14, the score being worked out retrospectively. Liston and $\mathrm{La}$ Rue suggested that infarcts as a cause of dementia were underestimated because only half of the brain was subjected to histopathological examination. Other prospective studies have failed to verify the type of dementia by necropsy, ${ }^{10-12}$ although one such study, that of Molsa et $a l$, did so. ${ }^{13}$ They examined the right half of the brain of 58 patients with a mean age of $79 \cdot 2$ years. They found that 28 patients had Alzheimer's disease, 17 had a vascular cause for their dementia (multi-infarct or mixed), and 13 had other causes for their disease. They reported that the diagnosis made before death had been correct in $60 \%$ of patients. There had been a tendency to overdiagnose multi-infarct dementia before death, which is contrary to our finding. The Hachinski score correctly distinguished between Alzheimer's disease and multi-infarct dementia in $64 \%$ of cases.

The difficulties of performing computed tomography in the elderly were highlighted by our study. Most of the scans were performed in 1983, and the new, higher resolution scanner that is now in use should give greater detail and more accurate help with diagnosis. Certain problems of performing computed tomography on the confused elderly will, however, remain. Two of our patients refused and in two cases the scans were of poor quality because of artefacts caused by movement. Other problems include interpreting ventricular enlargement in the elderly, whose brains undergo a degree of atrophy with normal aging; interobserver and intraobserver variation in reporting scans; and low rates of detection of reversible disorders (for example, the patient whose scan showed hydrocephalus did not have ventricular shunting). ${ }^{115}$

Although we spent more time and did more investigations than could reasonably be expected to be available in an average district general hospital, the rate of accuracy in diagnosing the type of dementia in our patients was just over $50 \%$. Although the numbers in our study were small and caution must be taken in extrapolating from such small numbers to general clinical practice, some important implications emerged.

Firstly, all clinicians strive for greater diagnostic accuracy, and the fact that three patients had completely unsuspected causes of their cognitive impairment (progressive multifocal leucoencephalopathy, pseudodementia, and diffuse Lewy body disease) is worrying. Secondly, the patient's history and a thorough clinical examination are of paramount importance in assessment, and better investigations, in addition to computed tomography, are needed to help with the diagnosis. Possibly in the future greater emphasis will be put on other diagnostic tools such as nuclear magnetic resonance scanning or brain stem evoked potentials. ${ }^{1+16}$ Thirdly, there are important implications for treatment to prevent cerebrovascular disease associated with hypertension and treatment of Alzheimer's disease itself. ${ }^{17}$ The validity of drug trials on pätients diagnosed as having Alzheimer's disease must be suspect unless the diagnosis is confirmed pathologically. Finally, clinicians must be confident of their diagnosis when counselling patients and their carers. Awareness of Alzheimer's disease and its implications for close relatives is increasing. Patients with dementia due to other causes may actually have a family history of dementia ${ }^{i x}$; it is uncommon for very elderly patients with Alzheimer's disease to have a positive family history, ${ }^{12}{ }^{20}$ but three of the four cases with Alzheimer's disease in our study did have a family history of dementia.

Our results show the importance of investigating the demented elderly and the value of allocating a bed for these patients and establishing teamwork in making the diagnosis. The clinical diagnosis in life should be verified by neuropathological studies. When resources improve all patients referred with dementia should be properly investigated.

We thank Dr J Ambrose for reporting the computed tomograms, and the doctors, nurses, therapists, and technicians whose help made this study possible.

\section{Hachinski VC, Linette D, Zilhka E, et al. Cerebral blood flow in dementia. Arch Neurol 1975;32:632-7.}

2 Marsland TA, Glees P, Erickson LB. Modification of the (ilees silver impregnation for paraffin sections. I Neuropathol Exp Neurol 1954;13:587.

3 Tomlinson B, Blessed G, Roth M. Observations on the brains of demented old people. F Neurol Sci 1970;11:205-42

+ Erkinjuntti $T$, Wikstrom J, Palo J, et al. Dementia among medical inpatients, examination of 2000 consecutive admissions. Arch Intern .Med 1986;146: 1923-6.

5 Kay DW, Beamish P, Roth M. Old age mental disorders in Newcastle upon Tyne. 1. A study of prevalence. Br Y Psychiatry 1964;110:146-58.

6 Henderson AS. The epidemiology of Alzheimers disease. Br Med Bull 1986;42:3-10.

7 Liston EH, La Rue A. Clinical differentiation of primary degenerative and multi-infarct dementia: a critical review of the evidence. Part II. Pathological studies. Biol Psychiatry 1983:18:1467-84.

8 Gustafson L, Nilsson L. Differential diagnosis of presenile dementia on

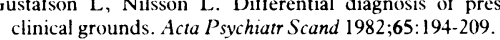

9 Rosen WG. Terry RD, Fuld PA, et al. Pathological verification of ischaemic score in differentiation of dementias. Ann Neurol 1980;7:487-8

10 Harrison MJG, Thomas DJ, DuBoulay $(\mathrm{GH}$, et al. Multi-infarct dementia. Harrison MJG, Thomas DJ, D
I Neurol Sci 1979;40:97-103.

11 Larson EB, Reifler BV, Featherstone HJ, et al. Dementia in elderly outpatients; a prospective study. Ann Intern Med 1984;100:417-23.

12 Smith JS, Kiloh LG, Ratnavale GS, et al. The investigation of dementia. The results in 100 consecutive admissions. Med J A ust 1976;2:403-5.

13 Molsa PK, Paljarvi L, Rinne JO, et al. Validity of clinical diagnosis in dementia: a prospective clinicopathological study. $\mathcal{J}$ Neurol Neurosur Psychiatry 1985;48:1085-90.

14 McGeer PL. Brain imaging in Alzheimer's disease. Br. Med Bull 1986;42:24-8. 15 Mulley GP. Differential diagnosis of dementia. Br. Med f 1986;292:1416-8.

16 Wright $G$, Scott LC, Richardson CE, et al. Event related potentials in dementia. Gerontology (in press).

17 Summers WK, Majovski LV, Marsh GM, et al. Oral tetrahydroaminoacridine in long-term treatment of senile dementia, Alzheimer type. $N$ Engl $\mathcal{G ~ M e d ~}$ 1986;315:1241-5.

18 Sulkava R, Haltia $M$, Paetau A, et al. Accuracy of clinical diagnosis in primary degenerative dementia; correlation with neuropathological findings. degenerative dementia; correlation with
I Neurol Neurosurg Psychiatry 1983;46:9-13.

19 Sulkava R. Alzheimer's disease and senile dementia of Alzheimer type. Acte Neurol Scand 1982;65:636-50.

20 Kay DWK. The genetics of Alzheimer's disease. Br.Med Bull 1986;42:19-24

(Accepted 17 fune 1988

\section{ONE HUNDRED YEARS AGO}

When any question is raised as to the wisdom or otherwise of certain modes or habits in regard to dress, it is commonly supposed that it is only foolish women or helpless children who require advice. There are perhaps at least as many men as women who suffer from the effects of cold through injudicious neglect of the clothing suitable for winter use, and thus contract sciatica, rheumatism, or pneumonia. Men acquire lumbago from the open coat and the waistcoat with a cotton back, but which ought to be lined with flannel. Not only do men frequently neglect to use an overcoat with the commencement of the cold season, but often they will leave the frock-coat unbuttoned, so that it becomes almost useless in a cold wind as a means of protecting the loins. Tight kid gloves and tight thin boots are frequent causes of cold hands and chilled feet, especially when accompanied by the persistent use of thin socks. When there is a known tendency to catarrh, or delicacy of lungs, the garments should be made wellfitting round the neck, and the collar not too loose and open, the waistcoat buttoning high, while continuous flannel undergarments are used uniformly over the body. The dress clothes being so much thinner than those worn during the day, it is well that in winter a high-fitting waistcoat be used under the shirt to protect the trunk. These and many other common-sense points as to winter dress are frequently neglected till mischief has occurred, or a warning has taught wisdom. The wiser man is he who changes his clothing according to the weather in such a variable climate as ours. (British Medical fournal 1888;ii:953) 